\title{
Evaluation of phosphodiesterase l-based protocols for the detection of multiply damaged sites in DNA: the detection of abasic, oxidative and alkylative tandem damage in DNA oligonucleotides
}

Karen J. Bowman, Rachel Le Pla, Yves Guichard, Peter B. Farmer ${ }^{1}$ and George D. D. Jones*

Department of Oncology and ${ }^{1}$ Biomonitoring and Molecular Interactions Section, MRC Toxicology Unit, Hodgkin Building, University of Leicester, PO Box 138, Lancaster Road, Leicester LE1 9HN, UK

Received June 29, 2001; Revised and Accepted August 28, 2001

\begin{abstract}
It has been proposed that DNA multiply damaged sites (MDS), where more than one moiety in a local region ( $\sim 1$ helical turn, $10 \mathrm{bp}$ ) of the DNA is damaged, are lesions of enhanced biological significance. However, other than indirect measures, there are few analytical techniques that allow direct detection of MDS in DNA. In the present study we demonstrate the potential of protocols incorporating an exonucleolytic snake venom phosphodiesterase (SVPD) digestion stage to permit the direct detection of certain tandem damage, in which two lesions are immediately adjacent to each other on the same DNA strand. A series of prepared oligonucleotides containing either single or pairs of tetrahydrofuran moieties (F), thymine glycol lesions $\left(\mathrm{T}^{\mathrm{g}}\right)$ or methylphosphotriester adducts (Me-PTE) were digested with SVPD and the digests examined by either ${ }^{32} \mathrm{P}$-end-labelling or electrospray mass spectrometry. The unambiguous observation of SVPD-resistant 'trimer' species in the digests of oligonucleotides containing adjacent $F, T^{g}$ and Me-PTE demonstrates that the SVPD digestion strategy is capable of allowing direct detection of certain tandem damage. Furthermore, in studies to determine the specificity of SVPD in dealing with pairs of lesions on the same strand, it was found mandatory to have the two lesions immediately adjacent to each other in order to generate the trimer species; pairs of lesions separated by as few as one or two normal nucleotides behave principally as single lesions towards SVPD.
\end{abstract}

\section{INTRODUCTION}

Numerous cytotoxic agents are proposed to exert their deleterious effects via formation of lesions and adducts in genomic DNA. As well as producing 'simple' individual lesions/adducts, a number of agents, such as ionising radiation and certain chemotherapeutic drugs, are proposed to generate 'complex' multiply damaged sites (MDS) where several moieties in a local region of the DNA ( $\sim 10 \mathrm{bp})$ are damaged (1-4). These complex lesions are proposed to be of heightened biological significance due to the greater challenge they present repair systems (5).

Given the proposed significance of MDS, it is desirable to have analytical techniques that will allow their direct detection. To date, the most frequently studied DNA lesions which are taken as indices of MDS formation are immediate and latent DNA double-strand breaks (DSBs), the latter becoming apparent upon post-damaging treatment. Such treatment has included the use of damage-recognising endonucleases to convert base lesions into strand breaks, with noted increases in DSB formation being taken as indicative of the presence of base damage-containing MDS (6). However, these measures are somewhat indirect and are probable underestimates, as certain MDS have been shown to be refractory to endonuclease action $(7,8)$ and, furthermore, base lesions that comprise an immediate DSB-MDS will go undetected/unmeasured. In the present study we demonstrate the potential of protocols incorporating a phosphodiesterase I (snake venom phosphodiesterase, SVPD) digestion stage to allow direct detection of a subset/constituent of MDS, namely 'tandem' lesions, whereby two lesions are immediately adjacent to each other on the same DNA strand.

The choice of an SVPD digestion strategy is based on the observation that certain DNA lesions (including apurinic sites and thymine glycols) prevent SVPD-mediated hydrolysis of the adjacent $5^{\prime}$-internucleotide phosphodiester linkage (9-13). Therefore, digestion of damage-containing DNA with this enzyme [in the presence of DNase I and alkaline phosphatase (AP)] yields single damage as lesion-bearing dimer species, $\mathrm{dNpX}$, where the damage $(\mathrm{X})$ is $3^{\prime}$ to a normal nucleoside $3^{\prime}$-phosphate moiety (dNp-) (Scheme 1A). These species are ideal substrates for 5'-32P-end-labelling, via incubation with T4 polynucleotide kinase (T4 PNK) plus $\left[\gamma^{-32} \mathrm{P}\right] \mathrm{ATP}$, and this allows their ready detection [via sequencing PAGE and/or HPLC with radioactivity detection $\left.\left({ }^{32} \mathrm{P}-\mathrm{HPLC}\right)\right]$ as the corresponding $5^{\prime}-{ }^{32} \mathrm{P}$-end-labelled dimers, $\left.{ }^{32} \mathrm{P}\right] \mathrm{dNpX}$ (Scheme 1A). This protocol is the SVPD-based post-labelling assay described by Weinfeld and co-workers $(14,15)$. The assay has been used to detect radiation-induced thymine glycols $\left(\mathrm{T}^{\mathrm{g}}\right)$ and 
A

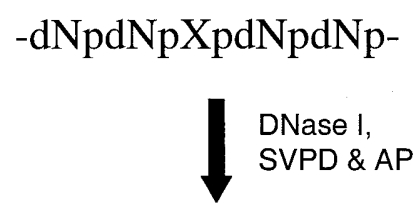

$\mathrm{dNpX}+(\mathrm{dN})_{\mathrm{n}}$

T4PNK \&

$\left[{ }^{32} \mathrm{P}\right]$ ATP

${ }^{32} \mathrm{P}-\mathrm{dNpX}$

PAGE or

${ }^{32}$ P-HPLC

QUANTITATION
B

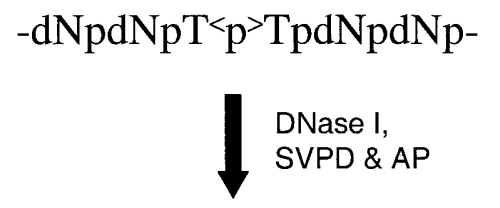

$\mathrm{dNpT}^{<} \mathrm{p}^{>} \mathrm{T}+(\mathrm{dN})_{\mathrm{n}}$

T4PNK \& [32P] ATP

${ }^{32} \mathrm{P}-\mathrm{dNpT}<\mathrm{p}>\mathrm{T}$

PAGE or

${ }^{32} \mathrm{P}-\mathrm{HPLC}$

QUANTITATION
OF LESIONS
C
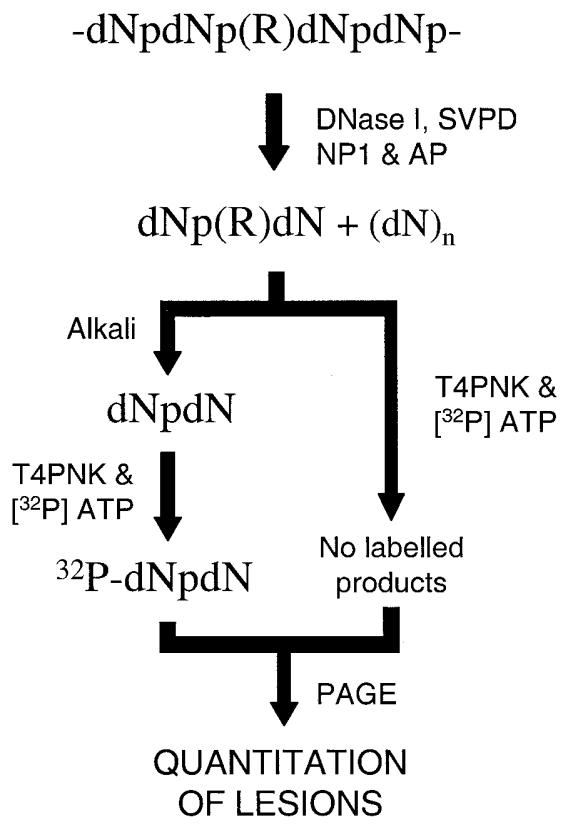

Scheme 1.

phosphoglycolate termini (14), to compare oxidative lesions produced by Fenton chemistry and ionising radiation (15) and to detect phosphoglycolate lesions produced in cellular DNA by oxidative stress (16). The assay has also been used to measure apurinic site formation in DNA (17) and to detect UV light-induced cyclobutane pyrimidine dimer $\left(T^{<} p^{>} T\right)$ formation (18). Intriguingly, the pyrimidine dimer lesions furnish the lesion-bearing trimer species, $\mathrm{dNpT}^{<} \mathrm{p}>\mathrm{T}$, after SVPD digestion and then the corresponding labelled trimers, $\left[{ }^{32} \mathrm{P}\right] \mathrm{dNpdT}<\mathrm{p}^{>} \mathrm{T}$, after phosphorylation with ${ }^{32} \mathrm{P}$ (18; Scheme 1B).

The SVPD-based post-labelling assay has been further developed for the detection of simple alkylphosphotriesters (19). The protocol is based on the inability of all known nucleolytic enzymes to cleave the internucleotide PTE bond (20,21). Consequently, complete digestion of alkylated DNA with SVPD plus nuclease P1 (NP1), in the presence of DNase I and $\mathrm{AP}$, yields PTE-dinucleoside phosphate species $[\mathrm{dNp}(\mathrm{R}) \mathrm{dN}]$ (Scheme 1C) (NP1 is included in the digestion to allow for the specific detection of alkylphosphotriesters, by hydrolysing any $\mathrm{dNpX}$ species that are generated as a result of base alkylation). These species are then converted to corresponding dinucleoside phosphates $(\mathrm{dNpdN})$, by treatment with alkali, to permit subsequent ${ }^{32} \mathrm{P}$-labelling (in the absence of alkali treatment, no labellable substrate is produced). The resulting labelled dinucleotides $\left(\left[{ }^{32} \mathrm{P}\right] \mathrm{dNpdN}\right)$ are then analysed by PAGE (Scheme 1C).

In a scenario analogous to that of the pyrimidine dimer lesions (see above), the presence of two SVPD-resistant lesions immediately adjacent to each other [i.e. $-\mathrm{dNpXpXpdN-} \mathrm{or}$ $-d N p(R) d N p(R) d N-]$ should yield the corresponding tandem damage-containing trimer species, $\mathrm{dNpXpX}$ or
$\mathrm{dNp}(\mathrm{R}) \mathrm{dNp}(\mathrm{R}) \mathrm{dN}$, after SVPD digestion (Scheme 2A and B). Thus, it should be practicable to exploit SVPD digestion to 'retain' certain tandem damage as $\mathrm{dNpXpX}$ or $\mathrm{dNp}(\mathrm{R}) \mathrm{dNp}(\mathrm{R}) \mathrm{dN}$ and then to use either ${ }^{32} \mathrm{P}$-end-labelling or an alternative form of analysis (i.e. semi-preparative HPLC combined with MS analysis) to effect their detection (Scheme 2A and B). To investigate this, a series of oligonucleotides 1-22 (Table 1) containing either single, tandem or pairs of separated tetrahydrofuran moieties (F) (oligonucleotides 1-8) (see Scheme 3A for tetrahydrofuran structure), thymine glycol lesions $\left(\mathrm{T}^{\mathrm{g}}\right.$ ) (oligonucleotides 9-16) (Scheme 3B) or methyl phosphotriester adducts [Me-PTE, denoted by $\mathrm{p}(\mathrm{Me})$ in Table 1] (oligonucleotides 17-22) (Scheme 3C) were prepared and exploited as model substrates to evaluate the SVPD-based digestion strategy as a means of detecting tandem damage. All of the oligonucleotides were prepared via routine automated phosphoramidite DNA oligonucleotide synthesis; the F- and Me-PTE-containing oligonucleotides using the appropriate phosphoramidite precursors, whilst the $\mathrm{T}^{\mathrm{g}}$-containing oligonucleotides were prepared from the corresponding thymidinecontaining oligonucleotides via $\mathrm{OsO}_{4}$-mediated oxidation (22). The F- and $\mathrm{T}^{\mathrm{g}}$-containing oligonucleotides were digested with SVPD, DNase I and AP, the digests were then subjected to semi-preparative HPLC and the isolated components examined by either ${ }^{32} \mathrm{P}$-end-labelling/PAGE or electrospray mass spectrometry. The Me-PTE-containing oligonucleotides were digested with SVPD, NP1, DNase I and AP and the digests, either untreated or treated with alkali, directly examined by ${ }^{32} \mathrm{P}$-end-labelling/PAGE. 
A

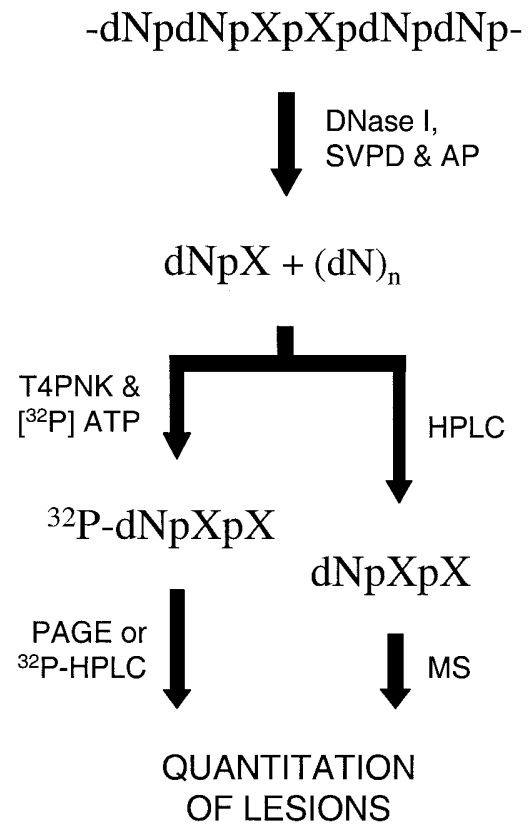

Scheme 2.

\section{MATERIALS AND METHODS}

\section{Materials}

The tetrahydrofuran-containing oligonucleotides 1-8, the thymidine-containing precursors to oligonucleotides 9-16 and the methylphosphotriester-containing oligonucleotides 17-22 were prepared via routine automated phosphoramidite DNA oligonucleotide synthesis by the Protein and Nucleic Acid Chemistry Laboratory (PNACL), University of Leicester, on the $1 \mu$ mol scale using an Applied Biosystems model 394 DNA/RNA synthesiser (PE Applied Biosystems, Warrington, UK). Oligonucleotides 1-8 and 17-22 were prepared using $5^{\prime}$-O - dimethoxytrityl-1', $2^{\prime}$-dideoxyribose- $3^{\prime}$ - [(2-cyanoethyl)- $(N, N$ -

diisopropyl)]-phosphoramidite (dSpacer CE phosphoramidite) and $5^{\prime}$ - $O$-dimethoxytrityl- $2^{\prime}$-deoxythymidine- $3^{\prime}-[(O$-methyl $)$ $(\mathrm{N}, \mathrm{N}$-diisopropyl)]-phosphoramidite (dT-Me phosphoramidite), respectively, according to the supplier's instructions (Glen Research, Sterling, VA). Phosphodiesterase I (Type IV from Crotalus atrox) (SVPD), DNase I and $\mathrm{OsO}_{4}$ were purchased from Sigma (Poole, UK), whilst T4 PNK and shrimp alkaline phosphatase (SAP) were purchased from US Biochemical (Cleveland, OH). [ $\left.\gamma^{32} \mathrm{P}\right] \mathrm{ATP}$ (Redivue, $>3000 \mathrm{Ci} / \mathrm{mmol})$ and poly $(\mathrm{dT})_{16}$ were purchased from Amersham Pharmacia Biotech (Little Chalfont, UK).

\section{$\mathrm{OsO}_{4}$ oxidation}

Samples of $50 \mathrm{nmol}$ oligonucleotides $\mathbf{9 , 1 0}$ and 13-16 and $25 \mathrm{nmol}$ samples of oligonucleotides $\mathbf{1 1}$ and $\mathbf{1 2}$ were incubated in $250 \mu \mathrm{l}$ of $50 \mu \mathrm{M} \mathrm{NH}_{4} \mathrm{OH}$ and $1 \% \mathrm{OsO}_{4}$ at room temperature for 0,6 or $48 \mathrm{~h}$. The oxidation reaction was stopped by extraction of
B

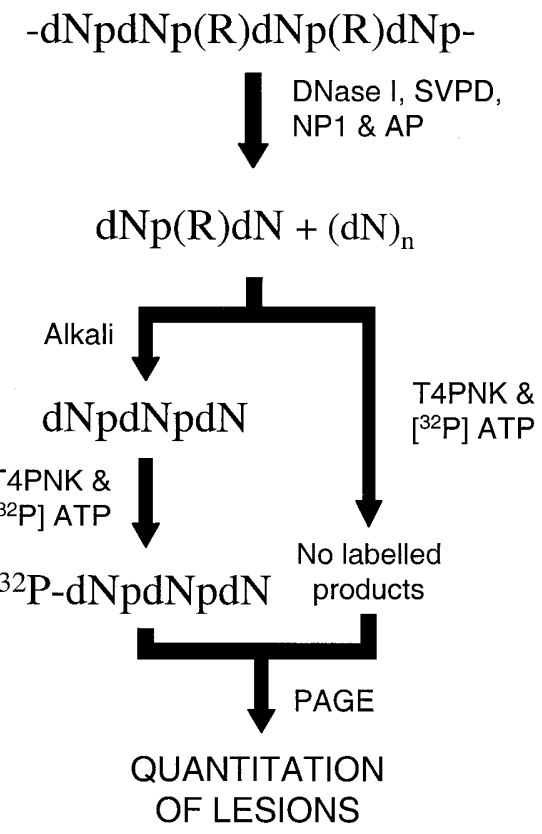

the $\mathrm{OsO}_{4}$ into $3 \mathrm{vol}$ of ether and the extraction repeated five times.

\section{Digestion}

Samples of $10 \mu \mathrm{g}$ oligonucleotides 1-8 and 9-16 were incubated with SVPD (0.04 U), DNase I (0.4 U) and SAP $(0.4 \mathrm{U})$ in $30 \mu \mathrm{l}$ of digestion buffer (10 mM Tris, $1 \mathrm{mM}$ EDTA, $4 \mathrm{mM} \mathrm{MgCl}$, $\mathrm{pH} 7.5)$ at $37^{\circ} \mathrm{C}$ overnight $(\sim 16 \mathrm{~h})$. The proteins were precipitated by addition of $3 \mathrm{vol}$ of ethanol, pelleted by centrifugation and aliquots of the ethanol supernatants dried by vacuum lyophilisation. The resulting dried residues were resuspended in distilled water $(0.1 \mu \mathrm{g} / \mu \mathrm{l})$ and then boiled $(10 \mathrm{~min})$ to inactivate residual nuclease and phosphatase activity, then stored at $-20^{\circ} \mathrm{C}$.

Similarly, $10 \mu \mathrm{g}$ samples of oligonucleotides 17-22 were incubated with SVPD (0.04 U), DNase I (0.4 U) NP1 (0.5 U) and SAP $(0.4 \mathrm{U})$ in $30 \mu \mathrm{l}$ of digestion buffer $(10 \mathrm{mM}$ Tris, $1 \mathrm{mM}$ EDTA, $4 \mathrm{mM} \mathrm{MgCl}_{2}, 2 \mathrm{mM} \mathrm{ZnCl}, \mathrm{pH} \mathrm{7.5)}$ at $37^{\circ} \mathrm{C}$ overnight $(\sim 16 \mathrm{~h})$. Again the proteins were precipitated by addition of $3 \mathrm{vol}$ of ethanol, pelleted by centrifugation and aliquots of the ethanol supernatants dried by vacuum lyophilisation. The resulting dried residues were resuspended in distilled water $(0.1 \mu \mathrm{g} / \mu \mathrm{l})$ and then boiled $(10 \mathrm{~min})$ to inactivate residual nuclease and phosphatase activity, then stored at $-20^{\circ} \mathrm{C}$.

\section{Alkali hydrolysis of PTE}

Alkali hydrolysis of the digested PTE-containing samples was carried out using aqueous ammonia. To an aliquot $(50 \mu \mathrm{l})$ of digest solution was added an equal volume of aqueous ammonia (25\%) and the reaction incubated in a tightly capped vial at $70^{\circ} \mathrm{C}$ for $24 \mathrm{~h}$. The reaction mixture was evaporated 
Table 1.

\begin{tabular}{|c|c|}
\hline Designation & Sequence \\
\hline \multicolumn{2}{|c|}{ Tetrahydrofuran $(\mathbf{F})$-containing oligonucleotides } \\
\hline 1 & $\mathrm{TpFpT}$ \\
\hline 2 & TpFpFpT \\
\hline 3 & $(\mathrm{Tp})_{5} \mathbf{F}(\mathrm{pT})_{5}$ \\
\hline 4 & $(\mathrm{Tp})_{5} \mathbf{F p} \mathbf{F}(\mathrm{pT})_{5}$ \\
\hline 5 & TpFpTpFpT \\
\hline 6 & ТрFрTрТрFрT \\
\hline 7 & $(\mathrm{Tp})_{5} \mathbf{F p T p} \mathbf{F}(\mathrm{pT})_{5}$ \\
\hline 8 & $(\mathrm{Tp})_{5} \mathbf{F p T p T p F}(\mathrm{pT})_{5}$ \\
\hline \multicolumn{2}{|c|}{ Thymine glycol $\left(\mathbf{T}^{\mathbf{g}}\right)$-containing oligonucleotides } \\
\hline 9 & $\mathrm{dAp} \mathbf{T}^{\mathrm{g}}$ \\
\hline 10 & $\mathrm{dAp} \mathbf{T}^{\mathrm{g}} \mathrm{p} \mathbf{T}^{\mathrm{g}}$ \\
\hline 11 & $(\mathrm{dAp})_{5} \mathbf{T}^{\mathrm{g}}(\mathrm{pdA})_{5}$ \\
\hline 12 & $(\mathrm{dAp})_{5} \mathbf{T}^{\mathrm{g}} \mathrm{p} \mathbf{T}^{\mathrm{g}}(\mathrm{pdA})_{5}$ \\
\hline 13 & dApT' $\mathbf{T}^{\mathrm{p} d A p} \mathbf{T}^{\mathrm{g}}$ \\
\hline 14 & $\mathrm{dAp} \mathbf{T}^{\mathrm{g}} \mathrm{pdApdAp} \mathbf{T}^{\mathrm{g}}$ \\
\hline 15 & $(\mathrm{dAp})_{5} \mathbf{T}^{\mathrm{g}} \mathrm{pdAp} \mathbf{T}^{\mathrm{g}}(\mathrm{pdA})_{5}$ \\
\hline 16 & $(\mathrm{dAp})_{5} \mathbf{T}^{\mathrm{g}} \mathrm{pdApdAp} \mathbf{T}^{\mathrm{g}}(\mathrm{pdA})_{5}$ \\
\hline \multicolumn{2}{|c|}{ Methyl phosphotriester $[\mathbf{p}(\mathbf{M e})]$-containing oligonucleotide } \\
\hline 17 & $\mathrm{Tp}(\mathbf{M e}) \mathrm{T}$ \\
\hline 18 & $\mathrm{~T} \mathbf{p}(\mathbf{M e}) \mathrm{T} \mathbf{p}(\mathbf{M e}) \mathrm{T}$ \\
\hline 19 & $(\mathrm{Tp})_{2} \mathrm{Tp}(\mathbf{M e}) \mathrm{T}(\mathrm{pT})_{7}$ \\
\hline 20 & $(\mathrm{Tp})_{2} \mathrm{~T} \mathbf{p}(\mathbf{M e}) \mathrm{T} \mathbf{p}(\mathbf{M e})(\mathrm{pT})_{7}$ \\
\hline 21 & $\mathrm{Tp}(\mathbf{M e}) \mathrm{Tp} T \mathbf{p}(\mathbf{M e}) \mathrm{T}$ \\
\hline 22 & $(\mathrm{Tp})_{2} \mathrm{~T} \mathbf{p}(\mathbf{M e}) \mathrm{TpT} \mathbf{p}(\mathbf{M e})(\mathrm{pT})_{6}$ \\
\hline
\end{tabular}

A
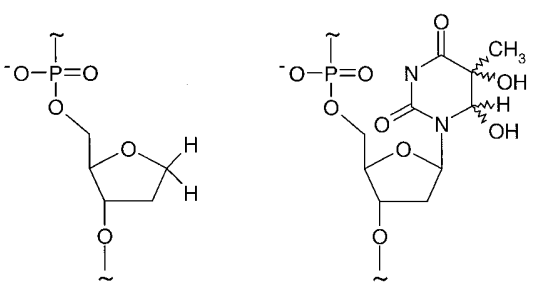

Scheme 3.

to dryness using a DNA centrifugal evaporator and the residue dissolved in an appropriate volume of water, then stored at $-20^{\circ} \mathrm{C}$.

\section{HPLC}

Reverse phase HPLC was performed on a Phase Sep Partisil $10 \mu \mathrm{m}$ ODS- 2 column $(250 \times 4.6 \mathrm{~mm}$ i.d. $)$ (Phase Separations Ltd, Deeside, UK). The HPLC instrumentation consisted of a Waters Alliance 2690 Separations Module coupled to a 484 Tuneable Absorbance Detector, equipped with Millennium 2010 Chromatography Manager software (Waters, Milford, MA). Aliquots of the digested oligonucleotides $(10 \mu \mathrm{g})$ were loaded onto the column and eluted using the following HPLC gradient. Solvent A: $0.1 \mathrm{M}$ triethylamine, $1 \%$ methanol, pH 5.0; solvent B: $100 \%$ methanol; gradient: 0 min, $0 \% \mathrm{~B}$; $10 \mathrm{~min}, 30 \% \mathrm{~B} ; 15 \mathrm{~min}, 30 \% \mathrm{~B} ; 20 \mathrm{~min}, 70 \% \mathrm{~B} ; 22.5 \mathrm{~min}$, $70 \% \mathrm{~B} ; 25 \mathrm{~min}, 0 \% \mathrm{~B}$. The flow rate was $1 \mathrm{ml} / \mathrm{min}$, with detection at $260 \mathrm{~nm}$. To isolate the material contained in each of the major peaks resolved, fractions of the eluant were collected at the appropriate times and dried by vacuum lyophilisation. The material in the peaks anticipated to contain the tetrahydrofuran-bearing 'dimer' (TpF) (i.e. peak 2 from oligos $\mathbf{1}, \mathbf{3}$ and 5-8) or the corresponding 'trimer' (TpFpF) (i.e. peak 2 from oligos 2 and 4 ) (see below) and material in all of the peaks for 9-16 were dissolved in distilled water to a calculated concentration of $100 \mu \mathrm{M}$ (based on quantitative recovery of $\mathrm{TpF}, \mathrm{TpFpF}, \mathrm{dApT}^{\mathrm{g}}$ or $\mathrm{dApT}^{\mathrm{g}} \mathrm{pT}^{\mathrm{g}}$ in any one fraction).

\section{Mass spectroscopy}

Aliquots of the HPLC isolated materials $(\sim 1 \mathrm{nmol})$ were diluted 10-fold with 70\% acetonitrile:30\% imidazole buffer $(50 \mathrm{mM})$ and the molecular weights assigned by negative ion electrospray mass spectrometry using a Micromass Platform (Micromass UK Ltd, Wythenshawe, UK).

\section{${ }^{32} \mathbf{P}$ Radiolabelling}

Aliquots of the HPLC isolated materials of 1-16 and aliquots of either the untreated or alkali-treated digests of 17-22 were diluted 1000-fold with distilled water and further aliquots containing $\sim 500 \mathrm{fmol}$ of potentially labellable substrate were incubated with T4 PNK (7.5 U), [ $\left.\gamma^{3}{ }^{32} \mathrm{P}\right] \mathrm{ATP}(3000 \mathrm{Ci} / \mathrm{mM}$, $1.65 \mathrm{pmol}$ ) and $\sim 100 \mathrm{fmol}$ poly $(\mathrm{dT})_{16}$ (when used as a labelling reference) in $10 \mu \mathrm{l}$ of kinase reaction buffer $(50 \mathrm{mM}$ Tris- $\mathrm{HCl}$, $\mathrm{pH}$ 7.6, $10 \mathrm{mM} \mathrm{MgCl} 2,10 \mathrm{mM}$ 2-mercaptoethanol) at $37^{\circ} \mathrm{C}$ for $1 \mathrm{~h}$. When poly $(\mathrm{dT})_{16}$ was used to consume excess $\left[\gamma^{3}{ }^{32} \mathrm{P}\right] \mathrm{ATP}$, the samples were incubated for an additional $30 \mathrm{~min}$ at $37^{\circ} \mathrm{C}$ with 40 pmol poly $(\mathrm{dT})_{16}$ plus a further quantity of T4 PNK (3.75 U). Following addition of an equal volume of formamide loading buffer [ $90 \%$ formamide, $0.02 \%$ bromophenol blue and $0.02 \%$ xylene cyanol in $1 \times$ TBE $(89 \mathrm{mM}$ Tris-borate, $\mathrm{pH} 8.3$, $2 \mathrm{mM}$ EDTA)], the radiolabelled products in a quarter of the mixture were separated by $20 \%$ denaturing PAGE using a Model S2 sequencing gel electrophoresis apparatus with either 1.6 or $0.8 \mathrm{~mm}$ spacers (Life Technologies, Paisley, UK). Electrophoresis was conducted at 1100-1200 V until the bromophenol blue had migrated either 11-12 cm (3-4 h) (oligonuceotides 1-8 and 17-22) or 25-26 cm (8-9 h) (oligonucleotides 9-16) and then, with the gel wrapped in cling-film, the radiolabelled products were visualised by contact autoradiography using Kodak X-Omat XAR-5 film $(30 \times 40 \mathrm{~cm})$. 

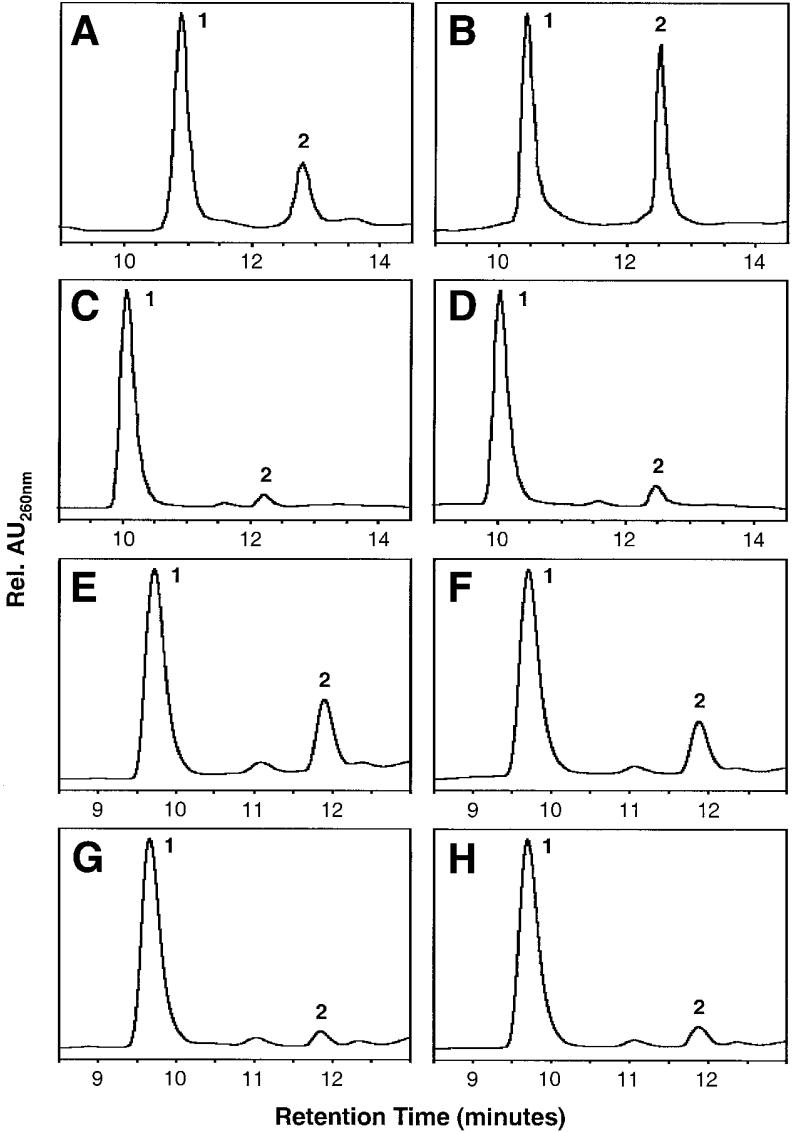

Figure 1. HPLC chromatographs showing digestion of the thymidylyl tetrahydrofuran-containing oligonucleotides 1-8 (A-H, respectively). The oligonucleotides were incubated with SVPD, DNase I and SAP at $37^{\circ} \mathrm{C}$ overnight and the isolated digests analysed by reverse phase HPLC as described in Materials and Methods.

\section{RESULTS}

\section{Tetrahydrofuran moieties}

The tetrahydrofuran-containing oligonucleotides 1-8 were treated with SVPD, DNase I and SAP and the isolated digests subjected to semi-preparative reverse phase HPLC as described in Materials and Methods. Figure 1A-D shows the HPLC chromatograms for the digests of oligonucleotides 1-4 (containing single and adjacent F) whilst Figure 1E-H shows the HPLC chromatograms for the digests of oligonucleotides 5-8 (containing pairs of separated F). In each instance, two principle peaks were resolved, peaks 1 and 2. Co-migration of the single peak of an authentic sample of thymidine (T) with peak 1 (data not presented) indicates that this peak contains $\mathrm{T}$. For 2 (Fig. 1B), peak 1 was of a similar size to peak 2, however, for 1, 3 and 4 (Fig. 1A, C and D) peak 1 was 3.8-, 20and 11-fold greater, respectively, compared to peak 2, whilst for 5-8 (Fig. 1E-H) peak 1 was 2.7-, 3.75-, 15.6- and 12.5-fold greater, respectively, compared to peak 2 .

The material contained in peak 2 of 1-8 was collected and aliquots analysed by ${ }^{32} \mathrm{P}$-end-labelling and by electrospray mass spectrometry. Figure $2 \mathrm{~A}$ shows the outcome of the endlabelling analysis for oligonucleotides 1-4 (containing single
A
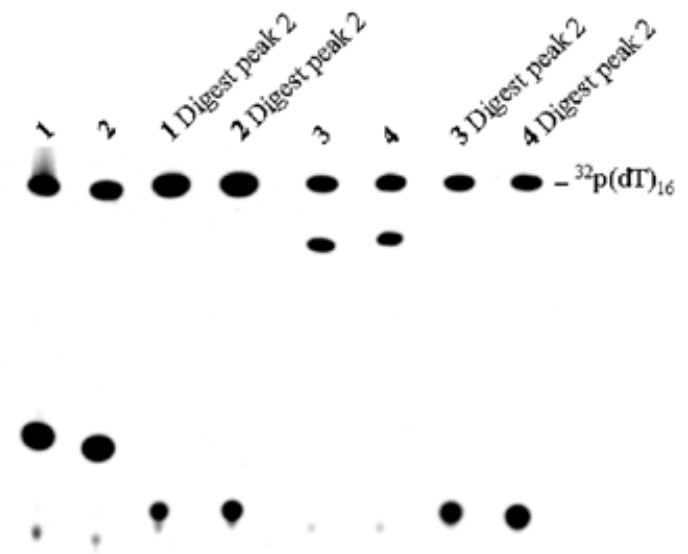

B
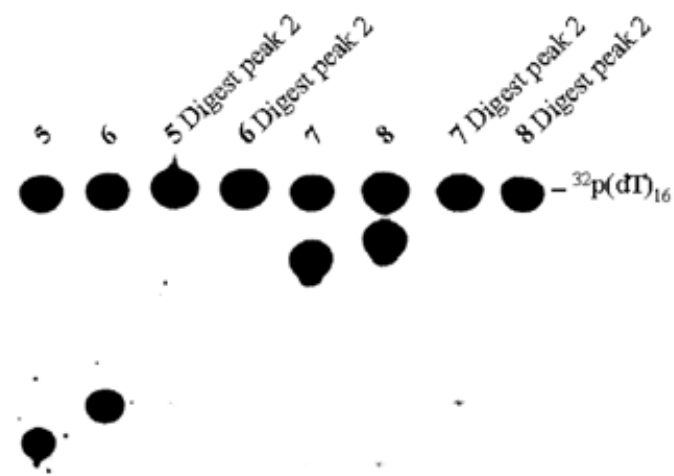

Residual ATP

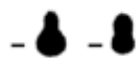

Figure 2. ${ }^{32} \mathrm{P}$-end-labelling analysis of the HPLC isolated material in peak 2 of the digests of oligonucleotides 1-8. The material contained in the HPLC isolated peaks was collected, aliquots incubated with $\left[\gamma-{ }^{32} \mathrm{P}\right] \mathrm{ATP}+\mathrm{T} 4 \mathrm{PNK}$ and the radiolabelled products analysed by PAGE as described in Materials and Methods. (A) The radiolabelled products from 1-4; (B) the radiolabelled products from 5-8. Poly $(\mathrm{dT})_{16}$ was used to consume the bulk of the excess $\left[{ }^{32} \mathrm{P}\right] \mathrm{ATP}$; the radiolabelled product, $\left[{ }^{32} \mathrm{P}\right](\mathrm{dT})_{16}$, remained near the top of the gel.

and adjacent F), while Figure $2 \mathrm{~B}$ shows the outcome of the end-labelling analysis for oligonucleotides 5-8 (containing pairs of separated F). From Figure 2A and B it is clear that for each oligonucleotide examined, peak 2 contains a species that is a substrate for T4 PNK-mediated ${ }^{32} \mathrm{P}$-end-labelling and that each labelled product migrates to approximately the same position under the conditions of electrophoresis used. End-labelling analysis of material from peak 1 of 1-8 revealed no labellable substrate present in this peak (data not presented). Figure 3A-D shows the electrospray ionisation mass spectra (negative mode) of the material contained in isolated peak 2 for oligonucleotides 1-4. This data, along with the electrospray mass spectrometry data for the material present in peak 2 of oligonucleotides 5-8, is presented in Table 2. For oligonucleotides $\mathbf{1}$ and $\mathbf{3}$ (containing a single F) peak 2 contained prominent negative ions $(\mathrm{M}-\mathrm{H})^{-}$of $\mathrm{m} / \mathrm{z} 421.6$ and 421.1, respectively (Fig. 3A and C), corresponding to TpF [calculated $(\mathrm{M}-\mathrm{H})^{-} \mathrm{m} / \mathrm{z}$ 421.3], while peak 2 from oligonucleotides 2 and 4 (containing 

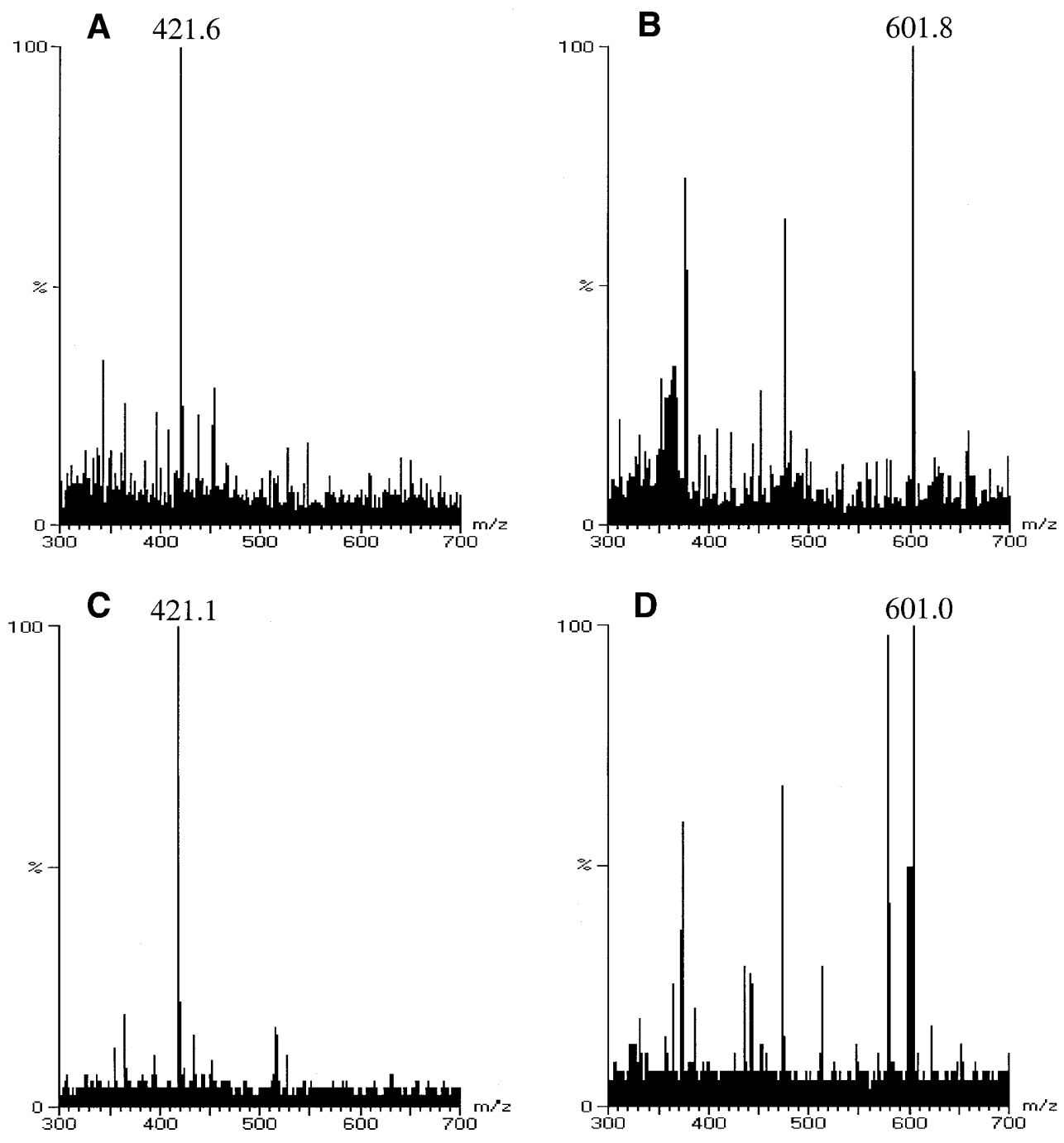

Figure 3. Electrospray mass spectra of the material contained in HPLC isolated peak 2 for oligonucleotides 1-4 (A-D, respectively).

adjacent $\mathrm{F}$ ) contained prominent negative ions $(\mathrm{M}-\mathrm{H})^{-}$of $\mathrm{m} / \mathrm{z}$ 601.8 and 601.0, respectively (Fig. 3B and D), corresponding to TpFpF [calculated $(\mathrm{M}-\mathrm{H})^{-} \mathrm{m} / \mathrm{z}$ 601.4]. For oligonucleotides 5-8 (containing pairs of separated $\mathrm{F}$ ), each peak 2 contained prominent negative ions $(\mathrm{M}-\mathrm{H})^{-}$of $m / z 421.6$ (Table 2), corresponding to $\mathrm{TpF}$.

\section{Thymine glycol lesions}

In preliminary experiments, the thymidine-containing precursors to oligonucleotides 9-16 were exposed to $\mathrm{OsO}_{4}$ for various times to determine the time required for stoichiometric oxidation of the thymidines in each oligonucleotide (data not presented). Consequently, oligonucleotides 9, 10, 13 and 14 (the shorter oligonucleotides) were prepared by exposure to $\mathrm{OsO}_{4}$ for $6 \mathrm{~h}$, while oligonucleotides 11, 12, 15 and 16 (the longer oligonucleotides) were prepared by exposure to $\mathrm{OsO}_{4}$ for $48 \mathrm{~h}$, as described in Materials and Methods. The stoichiometric production of the thymine glycol-containing oligonucleotides was confirmed by electrospray ionisation mass spectrometry (negative mode).
The thymine glycol-containing oligonucleotides 9-16 were treated with SVPD, DNase I and SAP and the digests subjected to semi-preparative reverse phase HPLC as described in Materials and Methods. Figure 4A-D shows the HPLC chromatograms for the digests of oligonucleotides 9-12 (containing single and adjacent $\mathrm{T}^{\mathrm{g}}$ ), while Figure 4E-H shows the HPLC chromatograms for the digests of oligonucleotides 13-16 (containing pairs of separated $\mathrm{T}^{\mathrm{g}}$ ). Generally, two principle peaks (or collection of peaks) were resolved by HPLC; peak 1 of retention time 12.9 min and peak(s) 2 of retention times -14-15.5 min. An exception was 10, for which there was a prominent peak at 13.8 min, denoted peak 1" (collected along with peak 1), and a significant 'tail' over 15.5-16.5 min, denoted 'peak' 3; for $\mathbf{1 3}$ and $\mathbf{1 4}$ a minor peak, peak 1', that eluted before peak 1 was also collected and analysed. Comigration of the single peak of an authentic sample of deoxyadenosine (dA) with peak 1 (data not presented) indicates that this peak contains dA.

Material from all of the denoted peaks was collected and aliquots analysed by ${ }^{32} \mathrm{P}$-end-labelling and by electrospray 
Table 2. Mass spectrometry data of the material contained in HPLC isolated peak 2 of oligonucleotides $\mathbf{1 - 8}$

\begin{tabular}{lllll}
\hline Sample & Peak number & $\begin{array}{l}\text { Retention time } \\
(\mathrm{min})\end{array}$ & $(\mathrm{M}-\mathrm{H})^{-}(\mathrm{m} / \mathrm{z})$ & $\begin{array}{l}\text { Proposed } \\
\text { structure }\end{array}$ \\
\hline $\mathbf{1}$ & 2 & 12.8 & 421.6 & $\mathrm{TpF}$ \\
$\mathbf{2}$ & 2 & 12.5 & 601.8 & $\mathrm{TpFpF}$ \\
$\mathbf{3}$ & 2 & 12.3 & 421.1 & $\mathrm{TpF}$ \\
$\mathbf{4}$ & 2 & 12.5 & 601.0 & $\mathrm{TpFpF}$ \\
$\mathbf{5}$ & 2 & 11.9 & 421.6 & $\mathrm{TpF}$ \\
$\mathbf{6}$ & 2 & 11.9 & 421.6 & $\mathrm{TpF}$ \\
$\mathbf{7}$ & 2 & 11.9 & 421.6 & $\mathrm{TpF}$ \\
$\mathbf{8}$ & 2 & 11.9 & 421.6 & $\mathrm{TpF}$ \\
\hline
\end{tabular}

mass spectrometry. Two samples were collected for peak 1 of 12; sample I between 12.5 and $13.0 \mathrm{~min}$ and sample II between 13 and $13.5 \mathrm{~min}$. Figure 5A shows the outcome of the endlabelling analysis for oligonucleotides 9-12 (containing single and adjacent $\mathrm{T}^{\mathrm{g}}$; end-labelling analysis of untreated $\mathbf{9}$ and $\mathbf{1 0}$ is also shown), while Figure 5B shows the outcome of the endlabelling analysis for oligonucleotides 13-16 (containing pairs of separated $\mathrm{T}^{\mathrm{g}}$ ); these particular gels were electrophoresed for 8-9 h in an attempt to improve the resolution of the labelled products. Interestingly, every HPLC peak was found to contain at least one species which was a substrate for T4 PNK-mediated ${ }^{32} \mathrm{P}$-end-labelling. The labelled species in the peaks for oligonucleotides 9-11 and 13-16 migrate as either one or two bands, whereas several labellable substrates were present for each peak for oligonucleotide 12. A different pattern of products was observed between samples I and II of peak 1 of oligonucleotide 12, suggesting that this peak contained several species. The species isolated from oligonucleotides $\mathbf{1 0}$ and $\mathbf{1 2}$ (containing adjacent $\mathrm{T}^{\mathrm{g}}$ ) were clearly poor substrates for $\mathrm{T} 4$ PNK-mediated ${ }^{32} \mathrm{P}$-end-labelling, as the band intensities are considerably lower than the band intensities for substrates isolated from the other oligonucleotides.

The electrospray ionisation mass spectra (negative mode) of the material contained in isolated peak 2 for oligonucleotides 9-12 (containing single and adjacent $\mathrm{T}^{\mathrm{g}}$ ) are shown in Figure 6A-D and this data, along with the electrospray mass spectrometry data for the material present in all of the denoted peaks of oligonucleotides 9-16, is presented in Table 3. For oligonucleotides 9 and $\mathbf{1 1}$ (containing a single $\mathrm{T}^{\mathrm{g}}$ ) all peaks contained prominent negative ions $(\mathrm{M}-\mathrm{H})^{-}$of $\mathrm{m} / \mathrm{z}$ 588.0-588.5 (see Fig. 6A and $\mathrm{C}$ ), corresponding to $\mathrm{dApT}^{\mathrm{g}}$ [calculated $(\mathrm{M}-\mathrm{H})^{-} \mathrm{m} / \mathrm{z}$ 588.5], while for oligonucleotides $\mathbf{1 0}$ and $\mathbf{1 2}$ (containing adjacent $\mathrm{T}^{\mathrm{g}}$ ) all peaks contained prominent negative ions $(\mathrm{M}-\mathrm{H})^{-}$of $\mathrm{m} / \mathrm{z}, 926.0-926.2$ (see Fig. 6B and D), corresponding to $\mathrm{dApT}^{\mathrm{g}} \mathrm{pT}^{\mathrm{g}}$ [calculated $(\mathrm{M}-\mathrm{H})^{-} \mathrm{m} / \mathrm{z}$ 926.7]. However, each peak from oligonucleotides 13-16 (containing pairs of separated $\mathrm{T}^{\mathrm{g}}$ ) contained a major ion $(\mathrm{M}-\mathrm{H})^{-}$of $\mathrm{m} / \mathrm{z}$ 588.0-588.2 (Table 3), corresponding to $\mathrm{dApT}^{\mathrm{g}}$.

\section{Phosphotriester adducts}

The methylphosphotriester-containing oligonucleotides 17-22 were treated with SVPD, DNase I, NP1 and SAP and the digests, either untreated or treated with alkali, analysed by

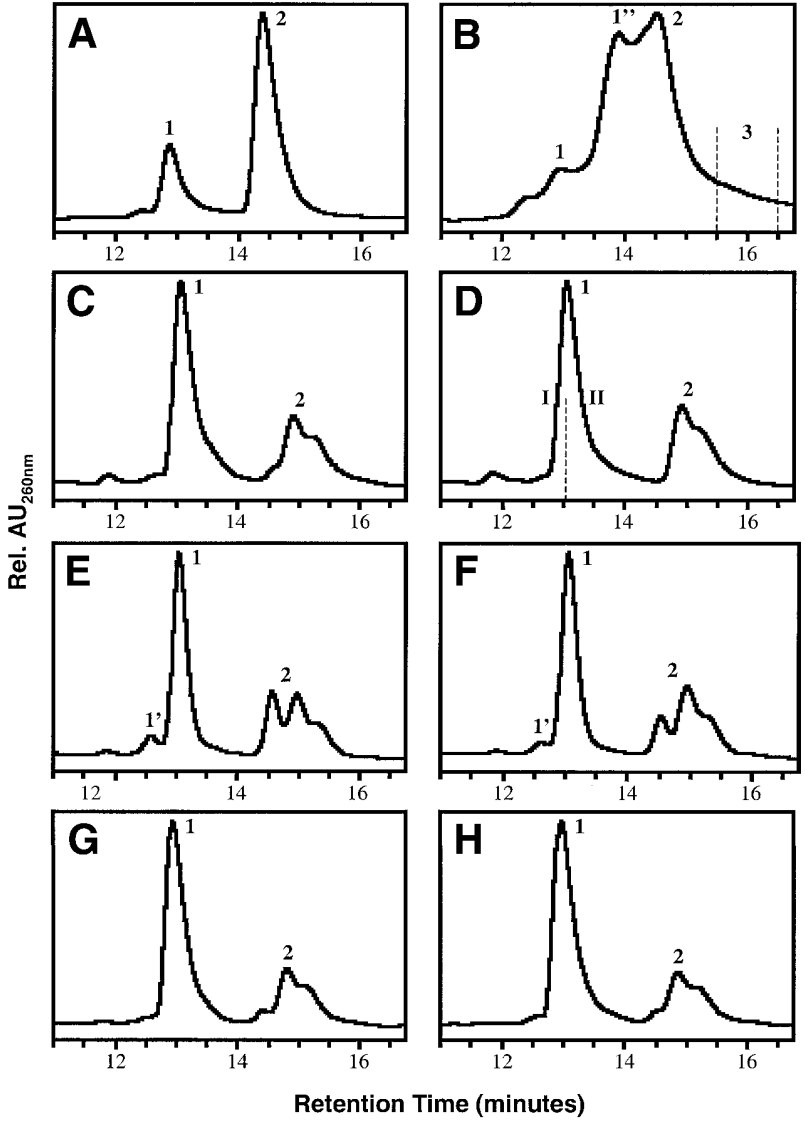

Figure 4. HPLC chromatographs showing digestion of the thymine glycolcontaining oligonucleotides 9-16 (A-H, respectively). The oligonucleotides were incubated with SVPD, DNase I and SAP at $37^{\circ} \mathrm{C}$ overnight and the isolated digests analysed by reverse phase HPLC as described in Materials and Methods.

${ }^{32} \mathrm{P}$-end-labelling as described in Materials and Methods. Figure 7A-D shows the outcome of the analysis of oligonucleotides 17-20 (containing single and adjacent Me-PTE) whilst Figure 7E and F shows the outcome of the end-labelling analysis of $\mathbf{2 1}$ and $\mathbf{2 2}$ (containing pairs of separated Me-PTE). Digestion, alkali treatment and end-labelling of $\mathbf{1 7}$ and $\mathbf{1 9}$ (containing single Me-PTE) leads to the formation of dimer $\left.{ }^{32} \mathrm{P}\right] \mathrm{TpT}(2 \mathrm{~T})$ (Fig. 7A and C). However, identical treatment of 18 and 20 (containing adjacent Me-PTE) leads to the formation of trimer $\left[{ }^{32} \mathrm{P}\right] \mathrm{TpTpT}(3 \mathrm{~T})$ plus some $2 \mathrm{~T}$ (Fig. 7B and D). Finally, digestion, alkali treatment and end-labelling of $\mathbf{2 1}$ and 22 (containing pairs of separated Me-PTE) leads to the formation of solely 2T (Fig. 7E and F). Analysis of the normal (non-PTE-containing) oligonucleotides leads to no labellable substrate (data not presented).

\section{DISCUSSION}

One type of MDS that has been the focus of extensive study is DNA DSB $(5,23)$. In DSB-MDS at least two single-strand breaks occur in close proximity ( $\sim 10 \mathrm{bp})$ on opposite strands of the DNA duplex. However, many other types of MDS are possible, including those consisting of pairs of lesions near or immediately adjacent (tandem) to each other on the same 
A
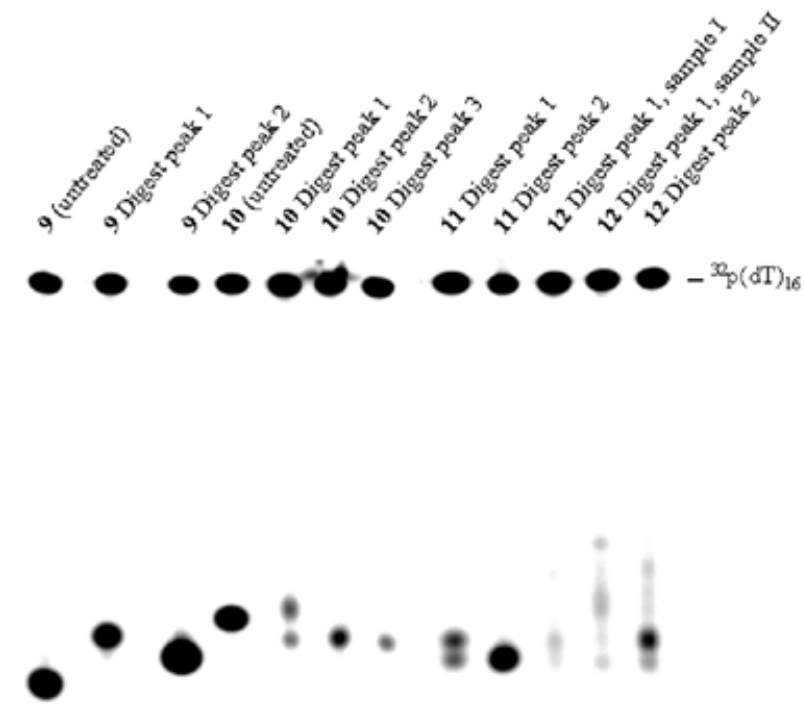

B
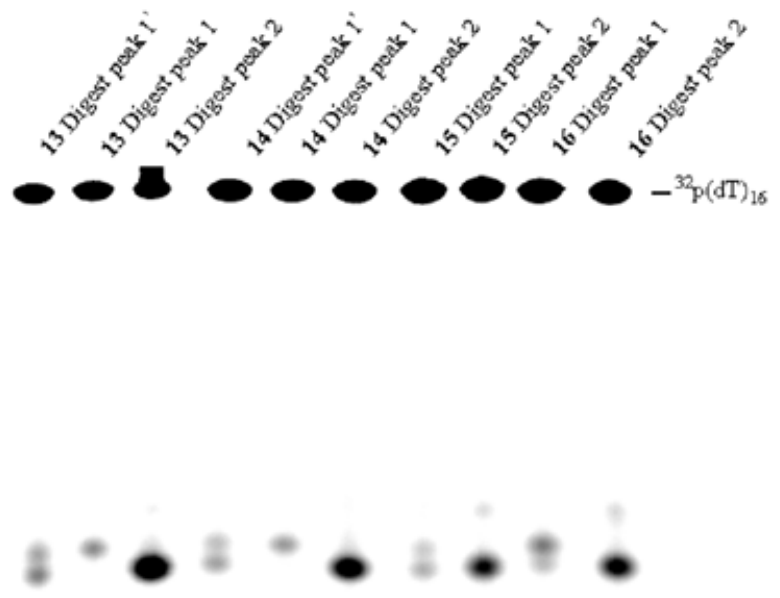

Figure 5. ${ }^{32} \mathrm{P}$-end-labelling analysis of HPLC isolated material from the digests of oligonucleotides 9-16. The material contained in HPLC isolated peaks was collected, aliquots incubated with $\left[\gamma_{-}{ }^{32} \mathrm{P}\right] \mathrm{ATP}+\mathrm{T} 4 \mathrm{PNK}$ and the radiolabelled products analysed by PAGE as described in Materials and Methods. (A) The radiolabelled products from 9-12; (B) the radiolabelled products from 13-16. Poly $(\mathrm{dT})_{16}$ was used to consume the bulk of the excess $\left[{ }^{32} \mathrm{P}\right] \mathrm{ATP}$; the radiolabelled product, $\left[{ }^{32} \mathrm{P}\right](\mathrm{dT})_{16}$, remained near the top of the gel.

strand $(5,24)$. In the present study, oligodeoxyribonucleotides containing either single, tandem or pairs of separated tetrahydrofuran moieties, thymine glycol lesions and methylphosphotriester adducts have been prepared as model substrates to examine protocols incorporating an SVPD digestion stage as potential methods to allow the analysis of certain tandem damage in DNA.

The tetrahydrofuran moieties (Scheme 3A) were initially chosen as model lesions with which to test the SVPD-based protocol as they represent stable abasic sites (stable to $\beta$-elimination) and as such they should confer resistance to SVPD hydrolysis on the $5^{\prime}$ phosphodiester bond (compare with 17). (For the sake of simplicity, when the tetrahydrofuran moieties, thymine glycol lesions and methylphosphotriester adducts are collectively discussed, they will be referred to as lesions, even though the tetrahydrofuran moieties are not considered true bona fide lesions.) These two properties, together with the ease of preparing oligonucleotides containing the tetrahydrofuran moieties at nominated positions by routine phosphoramidite DNA oligonucleotide synthesis procedures, provided us with ideal robust model oligonucleotide substrates with which to examine the SVPD digestion strategy as a means of detecting tandem damage. However, the tetrahydrofuran moieties are not 'true' lesions. Consequently, two other bona fide lesions/ adducts were included in the investigation. These were thymine glycol lesions (Scheme 3B), which are the major pyrimidine oxidative lesions produced by both ionising radiation and oxidative stress $(25,26)$, and alkylphosphotriester adducts (Scheme 3C), which are highly abundant and persistent adducts produced by potent alkylating agents $(27,28)$; for example, phosphotriesters constitute $>50 \%$ of the adducts generated by ethyl nitrosourea (28). Thymine glycols render the phosphodiester bond immediately $5^{\prime}$ to the glycol-bearing nucleoside refractory to SVPD-mediated hydrolysis $(11,14)$, whilst alkylphosphotriester formation renders the adducted phosphate moiety resistant to nuclease cleavage $(20,21)$.

SVPD is a $3^{\prime} \rightarrow 5^{\prime}$ exonuclease that digests both DNA and RNA. It requires a $3^{\prime}-\mathrm{OH}$ terminus for exonuclease activity and hydrolyses nucleic acids to release 5'-mononucleotides (29). SVPD interacts with the base $3^{\prime}$ to a phosphodiester linkage and certain modified bases (including thymine glycols) or a missing base (an abasic site) inhibit cleavage of the phosphodiester bond (9-13). Also, SVPD has an associated single strandspecific endonuclease activity (12). Consequently, prolonged digestion of damage-containing DNA with SVPD, in the presence of DNase I (to generate the required $3{ }^{\prime}-\mathrm{OH}$ termini) and an alkaline phosphatase (to hydrolyse phosphate monoesters), ultimately yields particular single damage as lesion-bearing dimer species, dNpX (12,15; Scheme 1A). Accordingly, digestion of oligonucleotides $\mathbf{1}$ and $\mathbf{3}$, containing a single $\mathrm{F}$, yielded labellable species of $m / z \sim 421$, corresponding to $\mathrm{TpF}$, while SVPD digestion of oligonucleotides 9 and 11, containing single $\mathrm{T}^{\mathrm{g}}$, yielded labellable species of $\mathrm{m} / \mathrm{z} \sim 588$, corresponding to $\mathrm{dApT}^{\mathrm{g}}$. Likewise, digestion, alkali treatment and labelling of $\mathbf{1 7}$ and 19, containing single Me-PTE, yielded the labelled dinucleotide $2 \mathrm{~T}$. However, the presence of some $2 \mathrm{~T}$ in the undigested/alkali non-treated control lane of 17 (Fig. 7A) indicated that a proportion of the starting material was demethylated; this unmethylated material was completely removed by digestion alone. For $\mathbf{1}$ and $\mathbf{3}$ the greater than predicted relative yield of released thymidine compared to recovered $\mathrm{TpF}$, as determined by HPLC analysis, indicates that the phosphodiester bond immediately $5^{\prime}$ to the $\mathrm{F}$ is indeed partially hydrolysed, $\sim 58 \%$ for 1 and $\sim 52 \%$ for 3 . Similar observations have been made previously for prepared $\mathrm{T}^{\mathrm{g}}$-containing dimers $\mathrm{dApT}^{\mathrm{g}}, \mathrm{dCpT}^{\mathrm{g}}$ and $\mathrm{dGpT}^{\mathrm{g}}$ whereby prolonged digestion with SVPD resulted in $\sim 50 \%$ loss of these dimer species as compared to digestion at shorter times (30). As mentioned above, it is proposed that phosphotriester lesions are refractory to nuclease digestion $(20,21)$.

SVPD digestion of oligonucleotides $\mathbf{2}$ and $\mathbf{4}$, containing adjacent $\mathrm{F}$, yielded a labellable species of $\mathrm{m} / \mathrm{z} \sim 601$, corresponding to TpFpF, while SVPD digestion of oligonucleotides 10 and 12, containing adjacent $\mathrm{T}^{\mathrm{g}}$, yielded (poorly) labellable 

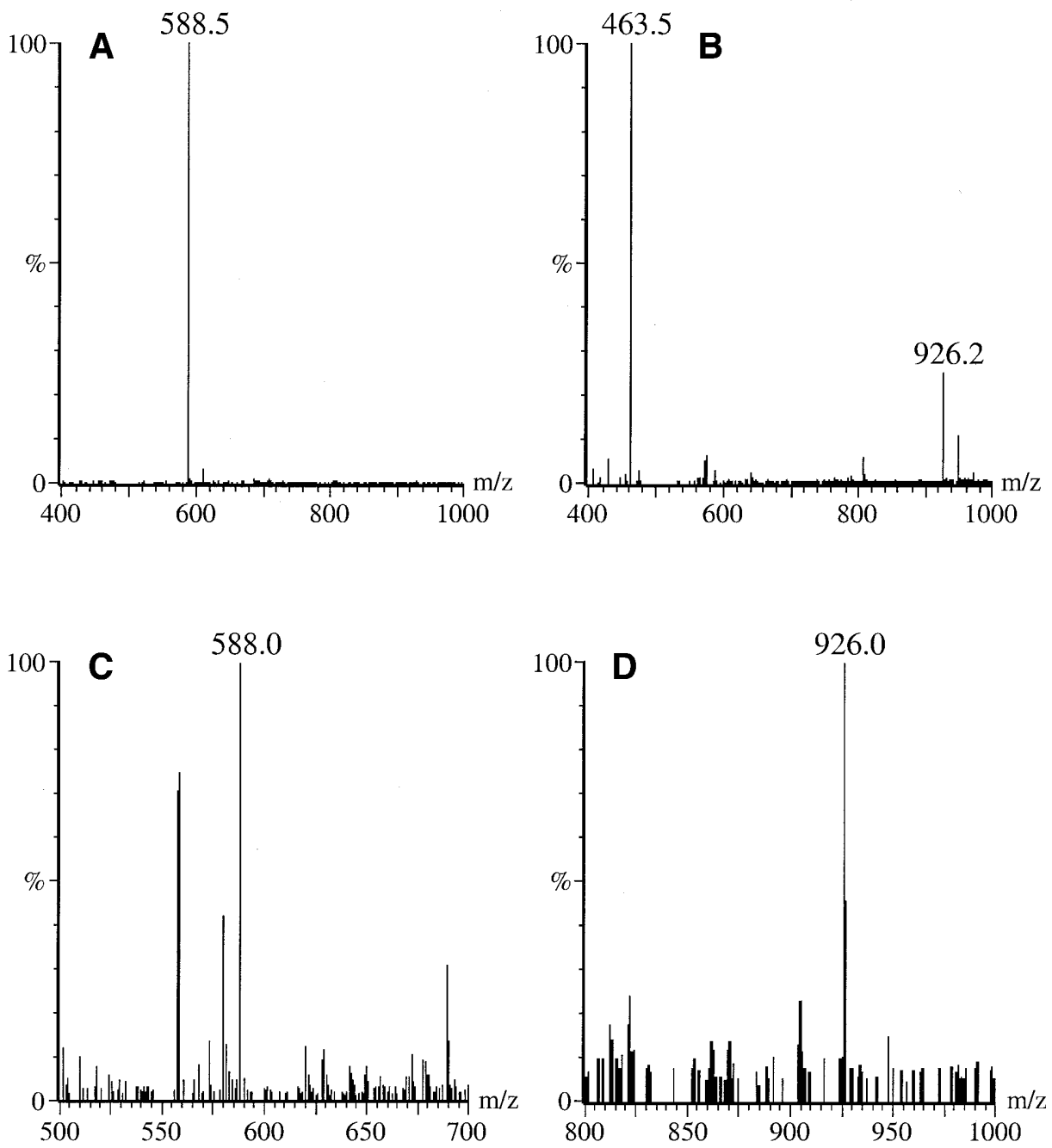

Figure 6. The electrospray mass spectra of the material contained in HPLC isolated peak 2 of oligonucleotides 9-12 (A-D, respectively).

species of $m / z \sim 926$, corresponding to $\mathrm{dApT}^{\mathrm{g}} \mathrm{pT}^{\mathrm{g}}$. Equally, digestion, alkali treatment and labelling of $\mathbf{1 8}$ and $\mathbf{2 0}$, containing tandem Me-PTE, yielded the labelled trinucleotide 3T. Again, the starting material was partially demethylated prior to analysis [leading to a slower migrating species, presumably $\left[{ }^{32} \mathrm{P}\right] \mathrm{TpTp}(\mathrm{Me}) \mathrm{T}$, being present in undigested/ alkali non-treated $\mathbf{1 8}$ (Fig. 7B), which was completely removed by digestion alone] and this in turn leads to the presence of some $2 \mathrm{~T}$ in the digested + alkali-treated lanes of both $\mathbf{1 8}$ and $\mathbf{2 0}$ (Fig. 7D). The higher ratio of recovered TpFpF versus released $\mathrm{T}$ for $\mathbf{2}$ and $\mathbf{4}$, compared to the ratio of recovered $\mathrm{TpF}$ versus released $\mathrm{T}$ for $\mathbf{1}$ and $\mathbf{3}$ (see above), indicates that the presence of tandem damage renders the phosphodiester bond immediately $5^{\prime}$ to the tandem furan entity further refractory to digestion by SVPD (compared to the lower degree of resistance afforded by a single F), to the extent that only $\sim 23 \%$ of these bonds are hydrolysed in $\mathbf{2}$ and $\sim 17 \%$ in $\mathbf{4}$.

By itself, ${ }^{32} \mathrm{P}$-end-labelling coupled with PAGE analysis was unable to distinguish between single and tandem F-containing species; the labelled species $\left[{ }^{32} \mathrm{P}\right] \mathrm{TpF}$ and $\left[{ }^{32} \mathrm{P}\right] \mathrm{TpFpF}$ migrate to approximately the same extent on PAGE analysis (see Fig. 2A) due to their comparable charge to mass ratios. Similarly, ${ }^{32} \mathrm{P}$-end-labelling coupled with PAGE was unable to clearly distinguish between the single and the tandem $\mathrm{T}^{\mathrm{g}}$-containing species (Fig. 5A); furthermore, the tandem $\mathrm{T}^{\mathrm{g}}$-containing species, dApT ${ }^{\mathrm{g}} \mathrm{pT}^{\mathrm{g}}$, were poor substrates for labelling compared to the single damage-containing species $\mathrm{dApT}^{\mathrm{g}}$. In order to distinguish between single and tandem $\mathrm{F}$ - and $\mathrm{T}^{\mathrm{g}}$ containing species it was necessary to exploit HPLC combined with 'off-line' MS analysis (HPLC+MS). Successful HPLC+MS-mediated detection of the TpFpF species in the digests of 2 and $\mathbf{4}$ (see Fig. 3B and D) and of the dApT ${ }^{g} \mathrm{pT}^{\mathrm{g}}$ species in the digests of $\mathbf{1 0}$ and $\mathbf{1 2}$ (see Fig. 6B and D) plus successful detection of $3 \mathrm{~T}$ in the digests of $\mathbf{1 8}$ and $\mathbf{2 0}$ by ${ }^{32} \mathrm{P}$-end-labelling/PAGE (see Fig. 7B and 7D) demonstrates that the SVPD digestion strategy is indeed capable of selectively retaining certain tandem damage and so allowing their direct detection.

Oligonucleotides 5-8, containing pairs of F separated by either one or two thymidine nucleotides, oligonucleotides 13-16, 
A

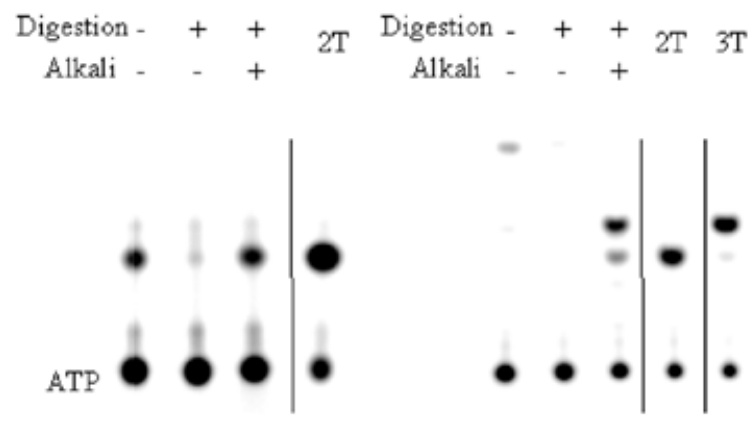

C

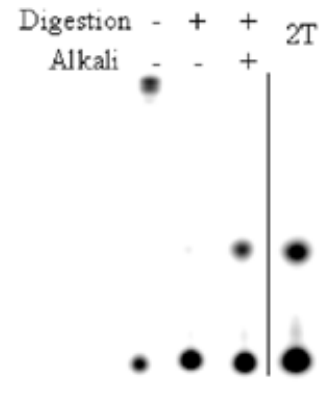

D

E

$\mathbf{F}$

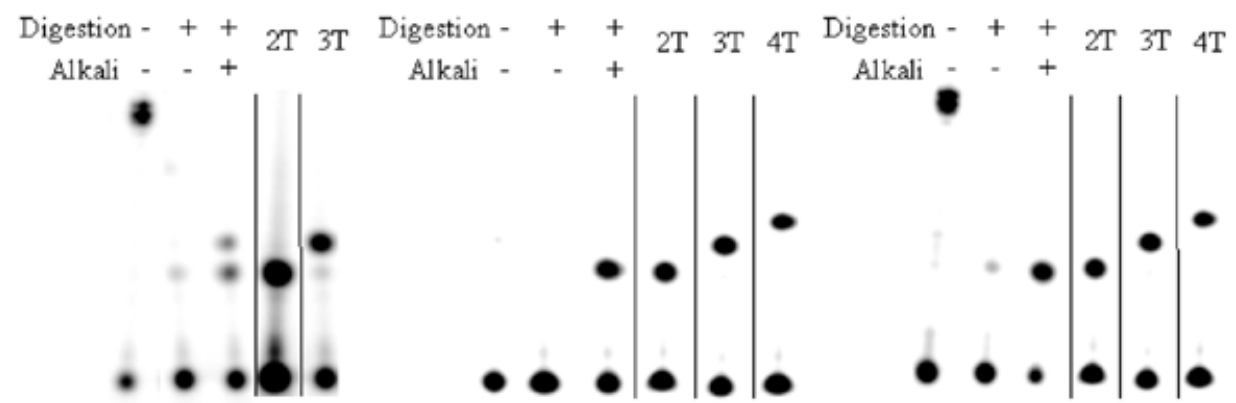

Figure 7. ${ }^{32} \mathrm{P}-$-end-labelling analysis of the digests of oligonucleotides 17-22 (A-F, respectively). The oligonucleotides were incubated with SVPD, DNase I, NP1 and SAP at $37^{\circ} \mathrm{C}$ overnight, aliquots of the digest (either untreated or treated with alkali) incubated with $\left[\gamma^{32} \mathrm{P}\right] \mathrm{ATP}+\mathrm{T} 4 \mathrm{PNK}$ and the radiolabelled products analysed by PAGE as described in Materials and Methods. A limiting amount of poly $(\mathrm{dT})_{16}$ was used as a labelling reference; the radiolabelled product, $\left.{ }^{32} \mathrm{P}\right](\mathrm{dT})_{16}$, remained near the top of the gel (not shown).

containing pairs of $\mathrm{T}^{\mathrm{g}}$ separated by either one or two deoxyadenosine nucleotides, and $\mathbf{2 1}$ and $\mathbf{2 2}$, containing pairs of Me-PTE separated by a single thymidylyl dinucleoside phosphate, were prepared to establish the specificity of SVPD in dealing with pairs of lesions on the same strand. In particular, these oligonucleotides were prepared to determine whether it was mandatory to have two lesions at adjacent positions in order to generate SVPD-resistant trimer fragments or whether pairs of lesions separated by normal nucleotides would also lead to longer SVPD-resistant fragments (i.e. TpFpTpF from $\mathbf{5}$ and 7 or TpFpTpTpF from $\mathbf{6}$ and 8). In every instance, SVPD digestion of oligonucleotides 5-8 yielded a labellable species of $\mathrm{m} / \mathrm{z} \sim 421$, corresponding to TpF, with no evidence for larger SVPD-resistant fragments apparent. Similarly, SVPD digestion of oligonucleotides 13-16 yielded a labellable species of $\mathrm{m} / \mathrm{z}$ $\sim 588$, corresponding to $\mathrm{dApT}^{\mathrm{g}}$, with no evidence for larger SVPD-resistant fragments apparent. For 5-8, the greater than anticipated relative yield of released thymidine compared to recovered $\mathrm{TpF}$, as determined by HPLC analysis, indicates that the phosphodiester bonds immediately $5^{\prime}$ to the individual separated tetrahydrofurans were hydrolysed to $\sim 55-65 \%$. This is similar to the extent of hydrolysis determined for the corresponding $5^{\prime}$ phosphodiester bond in the single Fcontaining oligonucleotides $\mathbf{1}$ and $\mathbf{3}$ (see above). Finally, digestion, alkali treatment and labelling of $\mathbf{2 1}$ and 22 exclusively yielded the labelled dinucleotide $2 \mathrm{~T}$, with no evidence for any longer fragments (i.e. $3 \mathrm{~T}$ or $\left[{ }^{32} \mathrm{P}\right] \mathrm{TpTpTpT}[4 \mathrm{~T}]$ ) apparent.

\section{CONCLUSIONS}

In the present study prepared oligodeoxyribonucleotides containing single, tandem or pairs of separated abasic, oxidative and alkylative damage were exploited as model substrates to examine protocols incorporating an SVPD digestion step as potential methods to permit the detection of tandem lesions in DNA. The successful HPLC+MS detection of tandem tetrahydrofuran- and thymine glycol-containing SVPD-resistant fragments in the digests of oligonucleotides containing these adjacent lesions, plus successful PAGE detection of the ${ }^{32} \mathrm{P}$-end-labelled trinucleotide species in the digests of oligonucleotides containing tandem methylphosphotriester adducts, demonstrates that the SVPD digestion strategy is indeed capable of retaining certain tandem damage and allowing their direct detection. In studies to determine the specificity of SVPD in allowing the detection of pairs of lesions on the same strand, it was found requisite to have the two lesions at immediately adjacent positions in order to generate the larger SVPD-resistant fragments; pairs of lesions separated by only one or two normal nucleotides behaved principally as single lesions towards SVPD digestion. Our future investigations will include studies to detect tandem lesions in DNA, as revealed by SVPD-based digestion, in combination with LC-MS 
Table 3. Mass spectrometry data of the material contained in HPLC isolated peaks of oligonucleotides 9-12

\begin{tabular}{|c|c|c|c|c|}
\hline Sample & Peak number & $\begin{array}{l}\text { Retention time } \\
(\mathrm{min})\end{array}$ & $(\mathrm{M}-\mathrm{H})^{-}(\mathrm{m} / z)$ & $\begin{array}{l}\text { Proposed } \\
\text { structure }\end{array}$ \\
\hline \multirow[t]{2}{*}{9} & 1 & 12.9 & 588.5 & $\mathrm{dApT} \mathrm{T}^{\mathrm{g}}$ \\
\hline & 2 & 14.4 & 588.5 & $\mathrm{dApT}^{\mathrm{g}}$ \\
\hline \multirow[t]{3}{*}{10} & $1+1^{\prime \prime}$ & $12.75-13.9$ & 926.0 & $\mathrm{dApT} \mathrm{T}^{\mathrm{g}} \mathrm{T}^{\mathrm{g}}$ \\
\hline & 2 & 14.5 & 926.2 & $\mathrm{dApT}^{\mathrm{g}} \mathrm{pT}^{\mathrm{g}}$ \\
\hline & 3 & $15.5-16.5$ & 926.2 & $\mathrm{dApT} \mathrm{T}^{\mathrm{g}} \mathrm{T}^{\mathrm{g}}$ \\
\hline \multirow[t]{2}{*}{11} & 1 & 13.1 & 588.0 & $\mathrm{dApT}^{\mathrm{g}}$ \\
\hline & 2 & 14.9 & 588.3 & $\mathrm{dApT} \mathrm{T}^{\mathrm{g}}$ \\
\hline \multirow[t]{3}{*}{12} & 1 (I) & 13.1 & 926.1 & $\mathrm{dApT}^{\mathrm{g}} \mathrm{pT}^{\mathrm{g}}$ \\
\hline & 1 (II) & 13.1 & 926.1 & $\mathrm{dApT}^{\mathrm{g}} \mathrm{pT}^{\mathrm{g}}$ \\
\hline & 2 & 14.9 & 926.1 & $\mathrm{dApT}^{\mathrm{g}} \mathrm{pT}^{\mathrm{g}}$ \\
\hline \multirow[t]{3}{*}{13} & $1^{\prime}$ & 12.6 & 588.1 & $\mathrm{dApT} \mathrm{T}^{\mathrm{g}}$ \\
\hline & 1 & 13.05 & 588.1 & $\mathrm{dApT} \mathrm{T}^{\mathrm{g}}$ \\
\hline & 2 & $14.5-15.5$ & 588.0 & dApT $T^{g}$ \\
\hline \multirow[t]{3}{*}{14} & $1^{\prime}$ & 12.6 & 588.1 & $\mathrm{dApT}^{\mathrm{g}}$ \\
\hline & 1 & 13.1 & 588.2 & $\mathrm{dApT} \mathrm{T}^{\mathrm{g}}$ \\
\hline & 2 & $14.5-15.5$ & 588.1 & $\mathrm{dApT} \mathrm{T}^{\mathrm{g}}$ \\
\hline \multirow[t]{2}{*}{15} & 1 & 12.9 & 588.2 & $\mathrm{dApT} \mathrm{T}^{\mathrm{g}}$ \\
\hline & 2 & $14.5-15.5$ & 588.1 & $\mathrm{dApT} \mathrm{T}^{\mathrm{g}}$ \\
\hline \multirow[t]{2}{*}{16} & 1 & 13.0 & 588.1 & $\mathrm{dApT} \mathrm{T}^{\mathrm{g}}$ \\
\hline & 2 & $14.5-15.5$ & 588.2 & $\mathrm{dApT}^{\mathrm{g}}$ \\
\hline
\end{tabular}

technology. A similar strategy has recently been reported by Cadet and co-workers for detection of $\mathrm{d} \beta \mathrm{F}$-8-oxodGuo tandem damage in $\gamma$-irradiated DNA (31).

\section{ACKNOWLEDGEMENTS}

The authors would like to thank Dr Kathryn Lilley and members of the Protein and Nucleic Acid Chemistry Laboratory (PNACL), Leicester University, for the preparation of oligonucleotides and analysis by mass spectometry and Mrs Lynda Langford for technical assistance. This work was supported by a MRC Project Grant (G95277655MA) and jointly by the University of Leicester and the MRC (JointFellowship to G.D.D.J.).

\section{REFERENCES}

1. Ward,J.F. (1985) Biochemistry of DNA lesions. Radiat. Res., 104, S103-S111.

2. Ward,J.F. (1997) Nature of lesions formed by ionizing radiation. In Nickoloff,J.A. and Hoekstra,M.F. (eds), DNA Damage and Repair, Vol. 2, DNA Repair in Higher Eukaryotes. Humana Press, Totowa, NJ, pp. $65-84$

3. Steighner,R.J. and Povirk,L.F. (1990) Bleomycin-induced DNA lesions at mutational hot-spots-implications for the mechanism of double strand cleavage. Proc. Natl Acad. Sci. USA, 87, 8350-8354.

4. Meschwitz,S.M., Schultz,R.G., Ashley,G.W. and Goldberg,I.H. (1992) Selective abstraction of $\mathrm{H}-2$ from $\mathrm{C}-\mathrm{1}^{\prime}$ of the C-residue in AGC.ICT by the radical center at $\mathrm{C}-2$ of activated neocarzinostatin chromophore- structure of the drug DNA complex responsible for bistranded lesion formation. Biochemistry, 31, 9117-9121.

5. Ward,J.F. (1988) DNA damage produced by ionizing radiation in mammalian cells: identities, mechanisms of formation and repairability. Prog. Nucleic Acid Res. Mol. Biol., 35, 95-125.

6. Prise,K.M., Pullar,C.H.L. and Michael,B. (1999) A study of endonuclease III-sensitive sites in irradiated DNA: detection of $\alpha$-particle-induced oxidative damage. Carcinogenesis, 20, 905-909.

7. Chaudry,A.M. and Weinfeld,M. (1997) Reactivity of human apurinic/ apyrimidinic endonuclease and Escherichia coli exonuclease III with bistranded abasic sites in DNA. J. Biol. Chem., 272, 15650-15655.

8. Harrison,L., Hatahet,Z., Purnal,A.A. and Wallace,S.S. (1998) Multiply damaged sites in DNA: interactions with Escherichia coli endonucleases III and VIII. Nucleic Acids Res., 26, 932-941.

9. Liuzzi,M., Weinfeld,M. and Paterson,M.C. (1989) Enzymatic analysis of trithymidylates containing ultraviolet light-induced cyclobutane pyrimidine dimers, I. nuclease P1-mediated hydrolysis of the intradimer phosphodiester linkage. J. Biol. Chem., 264, 6355-6363.

10. Weinfeld,M., Liuzzi,M. and Paterson,M.C. (1989) Selective hydrolysis by exo- and endonucleases of phosphodiester bonds adjacent to an apurinic site. Nucleic Acids Res., 17, 3735-3745.

11. Weinfeld,M. and Buchko,G.W. (1993) Postlabelling methods for the detection of apurinic sites and radiation-induced DNA damage. In Phillips,D.H., Castegnaro,M. and Bartsch,H. (eds), Postlabelling Methods for the Detection of DNA Adducts, IARC Scientific Publications no. 124. IARC, Lyon, pp. 95-103.

12. Stuart,C. and Chambers,R.W. (1987) Synthesis and properties of oligodeoxyribonucleotides with an AP site at a preselected position. Nucleic Acids Res., 15, 7451-7462.

13. Weinfeld,M., Soderlind,K.-J.M. and Buchko,G.W. (1993) Influence of nucleic acid base aromaticity on substrate reactivity with enzymes acting on single-stranded DNA. Nucleic Acids Res., 21, 621-626.

14. Weinfeld,M. and Soderlind,K.-J.M. (1991) ${ }^{32}$ P-Postlabelling detection of radiation-induced DNA damage: identification and estimation of thymine glycols and phosphoglycolate termini. Biochemistry, 30, 1091-1097.

15. Weinfeld,M., Liuzzi,M. and Jones,G.D.D. (1996) A postlabelling assay for oxidative damage. In Pfeifer,G.P. (ed.), Technologies for Detection of DNA Damage and Mutations. Plenum Press, New York, NY, pp. 63-71.

16. Bertoncini,C.R.A. and Meneghini,R. (1995) DNA strand breaks produced by oxidative stress in mammalian cells exhibit 3'-phosphoglycolate termini. Nucleic Acids Res., 23, 2995-3002.

17. Weinfeld,M., Liuzzi,M. and Paterson,M.C. (1990) Response of phage T4 polynucleotide kinase toward dinucleotides containing apurinic sites: design of a ${ }^{32} \mathrm{P}-$ postlabelling assay for apurinic sites in DNA. Biochemistry, 29, 1737-1743.

18. Weinfeld,M., Liuzzi,M. and Paterson,M.C. (1989) Enzymatic analysis of trithymidylates containing ultraviolet light-induced cyclobutane pyrimidine dimers, II. phosphorylation by phage T4 polynucleotide kinase. J. Biol. Chem., 264, 6364-6370.

19. Guichard,Y., Jones,G.D.D. and Farmer,P.B. (2000) Detection of DNA alkylphosphotriesters by ${ }^{32} \mathrm{P}$-postlabeling: the non-random manifestation of phosphotriester lesions in vivo. Cancer Res., 60, 1276-1282.

20. Miller,P.S., Fang,K.N., Kondo,N.S. and Ts'o,P.O. (1971) Syntheses and properties of adenine and thymine nucleoside alkyl phosphotriesters, the neutral analogs of dinucleoside phosphates. J. Am. Chem. Soc., 93, 6657-6665.

21. Gallo,K.A., Shao,K.L., Phillips,L.R., Regan,J.B., Koziolkiewicz,M., Uznanski,B., Stec,W.J. and Zon,G. (1986) Alkyl phosphotriester modified oligodeoxyribonucleotides. V. Synthesis and absolute-configuration of $\mathrm{rp}$ and sp diastereomers of an ethyl phosphotriester (Et) modified EcoRI recognition sequence, d[GGAA(Et)TTCC]—a synthetic approach to regiospecific and stereospecific ethylation-interference studies. Nucleic Acids Res., 14, 7405-7420.

22. Burton,K. and Riley,W.T. (1966) Selective degradation of thymidine and thymine deoxynucleotides. Biochem. J., 98, 70-77.

23. Illakis,G. (1991) The role of DNA double strand breaks in ionizing radiation-induced killing of eukaryotic cells. Bioessays, 13, 641-648.

24. Ward,J.F. (1994) The complexity of DNA damage: relevence to biological consequences. Int. J. Radiat. Biol., 66, 427-432.

25. von Sonntag,C. (1981) The Chemical Basis of Radiation Biology. Taylor \& Francis, London, UK.

26. Halliwell,B. (1998) Free Radicals in Biology and Medicine. Oxford University Press, Oxford, UK. 
27. Shooter,K.V. (1978) DNA phosphotriesters as indicators of cumulative carcinogen-induced damage. Nature, 274, 612-614.

28. Pegg,A.E. (1977) Formation and metabolism of alkylated nucleosides: possible role in carcinogenesis by nitroso compounds and alkylating agents. Adv. Cancer Res., 25, 195-269.

29. Razzell,W.E. and Khorana,H.G. (1959) Studies on polynucleotides. IV. Enzymic degradation. The stepwise action of venom phosphodiesterase on deoxyribo-oligonucleotides. J. Mol. Biol., 234, 2114-2117.
30. Routledge,M.N., Lunec,J., Bennett,N. and Jones,G.D.D. (1998) Measurement of basal levels of oxidative damage in human lymphocyte DNA by ${ }^{32} \mathrm{P}$-postlabelling. Proc. Am. Assoc. Cancer Res., 39, 287 (abstract 1961).

31. Bourdat,A.-G., Douki,T., Frelon,S., Gasparutto,D. and Cadet,J. (2000) Tandem base lesions are generated by hydroxyl radical within isolated DNA in aerated aqueous solution. J. Am. Chem. Soc., 122, 4549-4556. 